\title{
Article \\ Ovaries of Chrysanthemum Irradiated with High-Energy Photons and High-Energy Electrons Can Regenerate Plants with Novel Traits
}

\author{
Natalia Miler ${ }^{1, * \mathbb{C}}$, Iwona Jedrzejczyk ${ }^{2} \mathbb{D}$, Seweryn Jakubowski ${ }^{3}$ and Janusz Winiecki ${ }^{3,4}$ \\ 1 Laboratory of Ornamental Plants and Vegetable Crops, Faculty of Agriculture and Biotechnology, \\ UTP University of Science and Technology, Bernardynska 6, 85-796 Bydgoszcz, Poland \\ 2 Laboratory of Molecular Biology and Cytometry, Department of Agricultural Biotechnology, UTP University \\ of Science and Technology, Kaliskiego Ave 7, 85-796 Bydgoszcz, Poland; jedrzej@utp.edu.pl \\ 3 Department of Oncology and Brachytherapy, Collegium Medicum Nicholas Copernicus University in Torun, \\ 85-067 Bydgoszcz, Poland; jakubowskis@co.bydgoszcz.pl (S.J.); janusz@co.bydgoszcz.pl (J.W.) \\ 4 Medical Physics Department, Oncology Center in Bydgoszcz, 85-796 Bydgoszcz, Poland \\ * Correspondence: nmiler@utp.edu.pl
}

check for updates

Citation: Miler, N.; Jedrzejczyk, I.; Jakubowski, S.; Winiecki, J. Ovaries of Chrysanthemum Irradiated with High-Energy Photons and

High-Energy Electrons Can

Regenerate Plants with Novel Traits. Agronomy 2021, 11, 1111. https:// doi.org/10.3390/agronomy11061111

Academic Editors: Nadia Ficcadenti, Sara Sestili, Annalisa Giovannini and Daniela Palma

Received: 7 May 2021

Accepted: 27 May 2021

Published: 29 May 2021

Publisher's Note: MDPI stays neutral with regard to jurisdictional claims in published maps and institutional affiliations.

Copyright: (c) 2021 by the authors. Licensee MDPI, Basel, Switzerland. This article is an open access article distributed under the terms and conditions of the Creative Commons Attribution (CC BY) license (https:// creativecommons.org/licenses/by/ $4.0 /)$.

\begin{abstract}
Classical mutation breeding using physical factors is a common breeding method for ornamental crops. The aim of our study was to examine the utility of ovaries excised from irradiated inflorescences of Chrysanthemum $\times$ morifolium (Ramat.) as explants for breeding purposes. We studied the in vitro regeneration capacity of the ovaries of two chrysanthemum cultivars: 'Profesor Jerzy' and 'Karolina' preceded by irradiation with high-energy photons (total dose 5, 10 and 15 Gy) and high-energy electrons (total dose $10 \mathrm{~Gy}$ ). Growth and inflorescence parameters of greenhouse acclimatized regenerants were recorded, and ploidy level was estimated with flow cytometry. The strong impact of genotype on regeneration efficiency was recorded-cultivar 'Karolina' produced only 7 viable shoots, while 'Profesor Jerzy' produced totally 428 shoots. With an increase of irradiation dose, the regeneration decreased, the least responsive were explants irradiated with 15 Gy highenergy photons and 10 Gy high-energy electrons. Regenerants of 'Profesor Jerzy' obtained from these explants possessed shorter stem and flowered later. The highest number of stable, color and shape inflorescence variations were obtained from explants treated with 10 Gy high-energy photons. Variations of inflorescences were predominantly changes of shape-from full to semi-full. New color phenotypes were dark yellow, light yellow and pinkish, among them only the dark yellow phenotype remained stable during second year cultivation. None of the regenerants were haploid. The application of ovaries irradiated within the whole inflorescence of chrysanthemum can be successfully applied in the breeding programs, provided the mother cultivar regenerate in vitro efficiently.
\end{abstract}

Keywords: Chrysanthemum $\times$ morifolium (Ramat.), flow cytometry; in vitro regeneration; mutation breeding; ornamental plants; phenotypic variation

\section{Introduction}

\subsection{Classical Mutation Breeding in Modern Horticulture}

Although the site-directed CRISPR/Cas based technologies gain increasing interest in the plant breeding of essential crop plants, classical mutation breeding based on the concept of induction of random mutations, remains still an important method for breeding of ornamental plants [1,2]. The approach is currently a common tool exploited alongside with hybridization in the breeding programs of many crops, since it allows one to broaden the scope of variants without profoundly changing the whole genome of valued individuals [3]. Classical mutation breeding does not require the sophisticated molecular laboratories equipped with expensive devices, and employees with scientific degrees in genetic engineering; moreover, it is universal and does not demand deep knowledge of 
genes sequences, structures and functions-those advantages make it still an important and feasible method for commercial plant breeders [4].

Despite there are plenty of cultivars in the floricultural market, with Chrysanthemum $\times$ morifolium (Ramat.) being among the top most popular ornamentals (along with rose and carnation), the market needs are changing annually and there is a constant demand of novel plants creations [5]. Yearly numerous new chrysanthemum cultivars are submitted to grant plant breeders rights (PBR) in the European organization named Community Plant Variety Office (CPVO), being a counterpart of the patent office, for protection of breeders property [6]. Submitted cultivars undergo the procedure of confirmation their distinctiveness, uniformity and stability (so-called DUS tests) in greenhouse trials. Cuttings of a given cultivar provided by applying breeder in a specific amount (20 for chrysanthemums) are cultivated at the CPVO department to prove its uniqueness on the base of evaluation of their external features [7]. The main goal for ornamental breeding is to induce new traits in the appearance of plants, namely, color of flowers/inflorescences, shape of flowers, plant architecture and foliage variations [8]. These features can be easily changed with induced mutagenesis, provided one is equipped with efficient protocols for mutagenic treatment and regeneration, and with an attractive, mutable mother plant [2].

\subsection{Mutagenic Treatment}

Mutagenic factors deployed in plant breeding can be classified as chemical and physical mutagens. Among chemical mutagens, ethylmethanesulphonate (EMS) is utilized most often, however, pingyangmycin (PYM), an antibiotic used for cancer treatment in medicine, has been gaining more interest recently $[9,10]$. Physical mutagens, such as X- or gammarays, and heavy-ion beams are more environmental-friendly than chemical mutagens, since their utilization do not result in chemically harmful waste production. Unfortunately, the accessibility of the devices/facilities used for irradiation treatment can be a limiting factor for individual plant breeders. For acute irradiation of plants, there are usually utilized devices owned by national atomic agencies or scientific institutes [11,12]. For chronic gamma irradiation, there can be exploited so-called gamma fields or gamma-rooms, which are in total number of four, all of them located in the Eastern Asia [13]. Alternatively, a common microwave oven can be the source of mutagenic radiation, but the range of variations obtained could be unsatisfactory, since no color alternations in chrysanthemum were obtained this way so far [14].

A valuable and underestimated source of radiation for breeding purposes can be medicinal devices used for radiotherapy in oncological treatment, where high-energy photons and high-energy electrons are commonly applied. High-energy photons represent electromagnetic radiation in the range of X-rays, which is characterized by high beam energy, unlike X-rays used for diagnostic purposes in conventional X-ray machines [15]. High-energy electrons are generated with linear accelerators, and their application in tumor therapies, particularly at the high megavoltage, have increased recently [16]. The interaction of high-energy photons and electrons with the matter is different, since they have different physical nature. High-energy photons are highly penetrating, they do not possess a charge, and are responsible for indirect ionization of the matter [17]. Although highenergy electrons are less penetrative than photons, they produce much denser ionization within matter, since they possess a charge and cause primarily direct ionization, followed by secondary indirect ionization $[17,18]$. It is expected that due to different interaction with matter, a different type of radiation can lead to different mutation effects in plant breeding.

One of the advantages of utilization of clinical beams for breeding purposes is high precision of the application of radiation. The irradiated area can be accurately defined, moreover, the total dose is being precisely calculated and the radiation is aimed at the restricted irradiated area [16]. Consequently, if small plant parts are subjected to irradiation treatment, the accuracy of the total irradiation dose they absorbed is very high. 


\subsection{The Impact of Explant in Mutation Breeding}

In induced mutagenesis various plant parts (shoots bearing buds, organs performing adventitious regeneration and seeds) can be exposed to irradiation treatment and subsequently grown in vitro or/and in vivo for the expression of mutated traits $[2,9,19]$. In vitro adventitious regeneration is widely used in mutation breeding, since it provides a quick effect, relatively high variation percentage (as compared to meristem-bearing explants) and the lack of chimera plants [20]. Regeneration from non-meristematic explants as a method to obtain non-chimera mutants in chrysanthemums was first announced by Broertjes et al. [21] and had proven its applicability for many other species [22]. Numerous studies showed various response of different species and cultivars and explant types to regeneration efficiency-from abundant to poor [23]. Explants applied usually in the mutation breeding of chrysanthemum are: fragments of leaves and internodes, pedicels, nodal segments and less frequently, parts of inflorescences [9,11,19,24]. Ovaries have never been used for mutation breeding since now, both in chrysanthemum and in other species.

Ovaries are female reproductive organs sized 1-1.5 mm, located at the bottom of ligulate and disc florets in chrysanthemum. They are anchored in the receptacle and contain a single anatropous ovule wrapped with several layers of parenchyma cells and epidermis forming ovary wall [25].

Plant ovaries in breeding are mostly used as explants for haploids production and were successfully employed for this purpose in several species [26]. In chrysanthemum, the attempts to regenerate haploid plants from female organs were performed by Wang et al. [27] who dissected ovules form ovaries of distant-pollinated ligulate florets and resulted in only a single haploid plant among 2579 ovules inoculated. Miler and Muszczyk [28] elaborated an efficient two-step protocol for in vitro regeneration of plants from unpollinated ovaries dissected from ligulate florets in chrysanthemum. Unfortunately, despite the regenerants obtained in that research showing phenotypic and genetic variation, all of them remained hexaploids, similarly to the original 'Capitola', as detected by flow cytometry ploidy analysis. The results were interpreted that the regeneration underwent from somatic tissues [29]. Nonetheless, the inflorescence variations observed in that research, encouraged us to deploy ovaries as explants being a source of new variability for breeding. Moreover, surprisingly high regeneration capacity alongside with small size of the explants and their favorable location, (i.e., tight gathering in the inflorescence receptacle) make ovaries the convenient explants for irradiation with clinical devices.

The aim of the study was to evaluate the applicability of ovaries as explants for classical mutation breeding purposes in chrysanthemum. We estimated the impact of high-energy photons and high energy-electrons used as mutagenic factors on in vitro regeneration capacity of chrysanthemum ovaries and on subsequent growth and flowering of greenhouse cultivated plants and the ploidy of regenerants. We found out that with this approach new chrysanthemum cultivars can be obtained and the method can be successfully applied in the breeding programs, provided the mother cultivar efficiently regenerates in vitro.

\section{Materials and Methods}

\subsection{Plant Material}

Two cultivars of chrysanthemum (Chrysanthemum $\times$ morifolium/Ramat.) were chosen for the experiments: 'Profesor Jerzy' (pot type with large-sized, white, full and flat inflorescence) and 'Karolina' (spray type with middle-sized, purple, semi-full inflorescence) (Figure 1A,B). Donor plants for experiments were cultivated in a greenhouse in natural photoperiod, without any retardant treatments. 

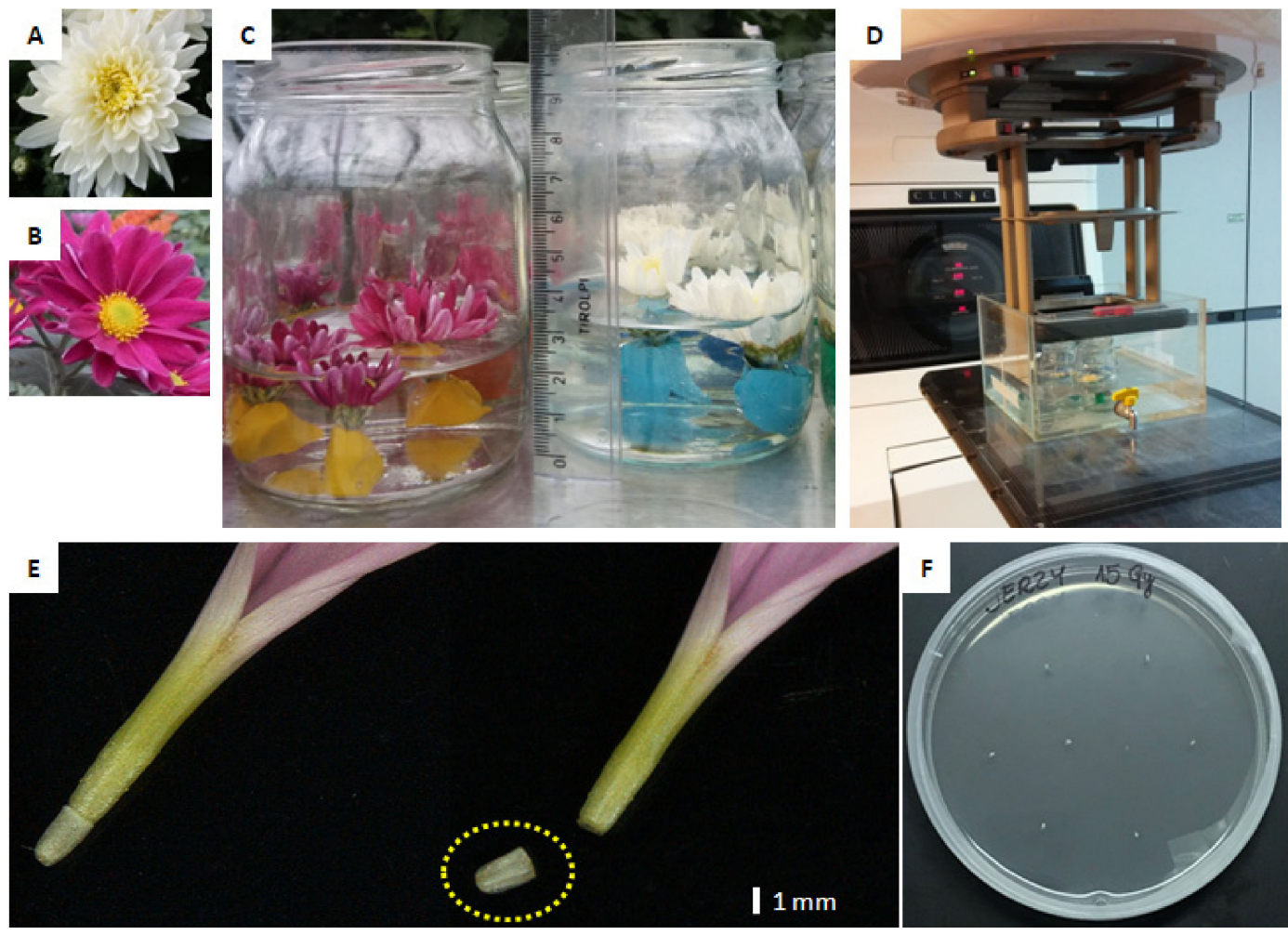

Figure 1. Inflorescences of the donor plants of chrysanthemums: (A) ‘Profesor Jerzy' and (B) 'Karolina'; (C) inflorescences prepared for irradiation with attached plastic clay loadings, immersed in water. Receptacles, where ovaries are located, were immersed approximately $2 \mathrm{~cm}$ deep. (D). Jars with inflorescences immersed in water in a polypropylene cubic container, just before high-energy electrons treatment. (E). Intact bottom part of ligulate floret of 'Karolina' (left) and after cutting off the ovary (right). (F). Ovaries placed onto Petri-dish directly after disinfection.

\subsection{Irradiation Treatments}

For the irradiation treatments, inflorescences of both cultivars, being at the same stage of maturity, were chosen. The stage of inflorescences maturity was as follows: outer three to five whorls of ligulate florets were fully developed, while internal whorls of ligulate florets (for 'Profesor Jerzy') or disc florets (for 'Karolina') were yet not fully developed. Inflorescences were cut off with a fragment of $0.5-1 \mathrm{~cm}$ of pedicles to which a pieces of plastic clay were attached to load it. Inflorescences prepared this way were put into $350 \mathrm{~mL}$ jars filled with distilled water to approximately half of volume, so the receptacles were immersed about $2 \mathrm{~cm}$ below water surface (Figure 1C). Each jar contained three inflorescences.

The objects were irradiated at the Oncology Center in Bydgoszcz, Poland. Conventional medical accelerators from Varian Medical Systems (Palo Alto, Santa Clara, CA, USA) were used for the experiment. Detailed characteristics of treatments including beam properties are presented in Table 1.

Three jars with inflorescences, prepared as described above, were put into a cubic polypropylene container filled with water (Figure 1D) and the beam accelerator was adjusted to aim the receptacles of irradiated inflorescences. Energy of irradiation was established at the same level for each treatment, namely $6 \mathrm{MeV}$. Inflorescences were treated with three total doses of high-energy photons (5, 10 and $15 \mathrm{~Gy}$; dose rate $3.19 \mathrm{~Gy} \mathrm{~min}^{-1}$ )

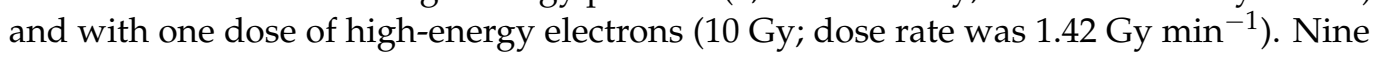
inflorescences per each treatment were used. 
Table 1. Characteristics of devices used for irradiation and treatments details.

\begin{tabular}{ccc}
\hline & \multicolumn{2}{c}{ Type of Irradiation } \\
\hline Characteristic & High-Energy Photons & High-Energy Electrons \\
\hline Device & Vitalbeam v. 2.7 & Clinac 2300CD Silhouette \\
Beam energy * & $6 \mathrm{MV}$ & $6 \mathrm{MeV}$ \\
Total dose delivered [Gy] & $5 ; 10 ; 15$ & 10 \\
Dose rate [Gy min ${ }^{-1}$ ] & 3.19 & 1.42 \\
Source-surface distance (SSD) [cm] & 100 & 100 \\
Depth [cm] & 2 & 2 \\
\hline
\end{tabular}

* Nominal accelerating potential (NAP) for photons.

\subsection{In Vitro Regeneration from Ovaries}

Irradiated inflorescences and control inflorescences (being at the same stage of maturity as irradiated ones, harvested directly from greenhouse cultivated plants) were used as a source of explants for experiment. The in vitro culture initialization was performed on the day of irradiation treatments.

For surface disinfection, whole inflorescences were first rinsed under running tap water for about $1 \mathrm{~min}$. Subsequently, ligulate florets of the outer three whorls from 'Profesor Jerzy' inflorescences, and all of the ligulate florets from 'Karolina' inflorescences were carefully detached from the receptacles and incubated for $10 \mathrm{~min}$ in distilled, sterile water with a drop of washing liquid. Afterwards, ligulate florets were immersed for $3 \mathrm{~s}$ in $70 \%$ ethanol, incubated for $5 \mathrm{~min}$ in a $0.5 \%$ sodium hypochlorite solution for disinfection and then washed two times for $5 \mathrm{~min}$ in sterile water.

Two-step protocol of in vitro regeneration from ovaries was performed according to procedure elaborated previously by Miler and Muszczyk [28] and refined by Miler and Jẹdrzejczyk [29]. Ovaries were cut off from the ligulate florets (Figure 1E) and put onto MS based medium [30] induction medium (step one), supplemented with $1.0 \mathrm{mg} \mathrm{dm}^{-3}$ benzyloaminopurine (BAP) and $1.0 \mathrm{mg} \mathrm{dm}^{-3}$ 2,4-dichlorofeoxyacetic acid (2,4-D), $\mathrm{pH}$ established prior to autoclaving at 5.8. Eight ovaries were cultured in $10 \mathrm{~cm}$ diameter Petri-dishes, 10 plates per treatment per cultivar (Figure 1F). Ovaries were cultured on an induction medium for 12 weeks in $16 \mathrm{~h} / 8 \mathrm{~h}$ day/night photoperiod under AP 67 LEDs (Valoya, Helsinki, Finland), photosynthetic photon flux density (PPFD) was $35 \mu \mathrm{mol} \mathrm{m}{ }^{-2} \mathrm{~s}^{-1}$, ambient temperature was $23 \pm 1{ }^{\circ} \mathrm{C}$. After the completion of induction step, percentage of sterile explants was recorded, diameters of calli regenerated around the ovaries were measured. Next, whole explants were transferred to glass-jars containing regeneration medium (step two) supplemented with $2.0 \mathrm{mg} \mathrm{dm}^{-3}$ kinetin, $1.0 \mathrm{mg} \mathrm{dm}^{-3}$ indoleacetic acid (IAA) and $4.0 \mathrm{mg} \mathrm{dm}^{-3}$ glycine, $\mathrm{pH}$ 5.8. Regeneration step lasted for 18 weeks in $16 \mathrm{~h} / 8 \mathrm{~h}$ day/night photoperiod under fluorescent tubes (Philips, Piła, Poland), PPFD was established at $35 \mu \mathrm{mol} \mathrm{m}{ }^{-2} \mathrm{~s}^{-1}$, ambient temperature was $23 \pm 1{ }^{\circ} \mathrm{C}$. After the completion of regeneration step, the percentage of explants regenerating shoots, mean numbers of shoots calculated as per inoculated and per regenerating explants were recorded for cultivars and for treatments.

Regenerated shoots were cut off, adjusted to $3-4 \mathrm{~cm}$ length and transferred onto solid rooting medium (MS based, supplemented with $2.0 \mathrm{mg} \mathrm{dm}^{-3}$ IAA, $\mathrm{pH}$ 5.8, vessels: glass-jars) and were cultured for 10 days in the same ambient conditions as described for the regeneration step. Along in that period plantlets produced short, having 1-2 $\mathrm{mm}$ of length, root primordia.

\subsection{Acclimatization and Greenhouse Cultivation of Regenerants}

Regenerated plants were cultivated in a greenhouse in two successive seasons (years) for traits expression and confirmation of their stability (recurrence of traits).

First season (2019): The rooted shoots derived from irradiated and control ovaries were acclimatized to greenhouse conditions for two weeks. They were planted in 66-cell trays (Figure 2) in a peat-moss based substrate with an addition of $30 \%$ of perlite, subse- 
quently covered with perforated transparent plastic film and regularly sprayed with water. Following two weeks of acclimatization, plantlets were transplanted and further cultivated in $11 \mathrm{~cm}$ diameter pots, one plant per pot. Plants grew vegetatively from June to August in natural photoperiod, they were watered 2-4 times weekly, and fertilized according to common practice, without pinching and retarding. Starting from September plants were subjected to short day (night phase from 6 PM to $8 \mathrm{AM}$ ) to induce flowering. Ambient relative humidity was $60-85 \%$, day/night temperature was $22 \pm 2{ }^{\circ} \mathrm{C} / 18 \pm 2{ }^{\circ} \mathrm{C}$.
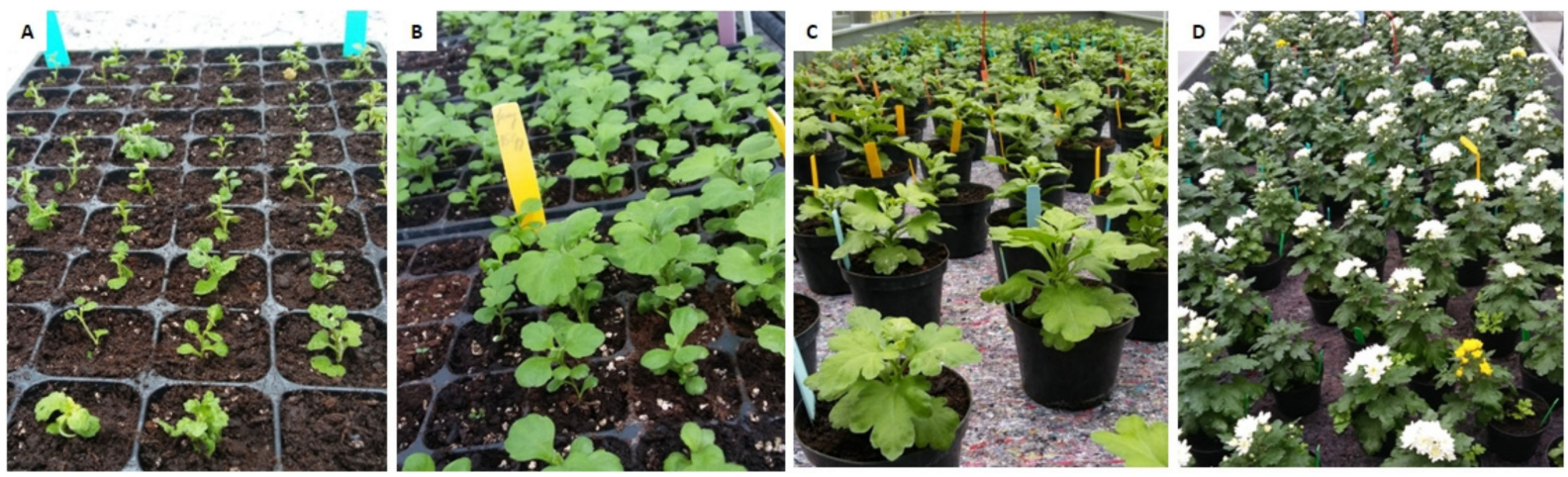

Figure 2. Cultivation of experimental 'Profesor Jerzy' plants in 2019. (A). Just after transplantation from in vitro culture. (B). After acclimatization. (C). Vegetative growth. (D). Flowering stage; among white inflorescences there are visible altered yellow ones.

The date of full flowering was recorded for each plant and plant height was measured. The type of inflorescence was indicated and the color of the inner side of florets was recorded according to the Royal Horticultural Color Chart (RHSCC). After all the inflorescences were harvested (in the middle of November), the shoots were cut $2 \mathrm{~cm}$ above the substrate surface and plants were left for a winter dormancy period in lower ambient temperature $\left(10 \pm 2{ }^{\circ} \mathrm{C}\right)$. Frequency of variation was estimated and expressed as the share (\%) of particular alterations in color and shape of regenerants as compared to reference plants.

Second season (2020): Starting from March plants were watered with a weak fertilizer solution to restart their growth and produced abundance of suckers, which were allowed to grow naturally. Plants (without transplantation) continued their vegetative and, subsequently, generative growth for the Summer and Autumn in the same conditions as described above. At the stage of full-flowering observations of inflorescence traits were performed, as described for year 2019. The recurrence of previous-year alternations was recorded.

In both seasons, inflorescences of regenerant plants, which originated from irradiated (and control) ovaries in vitro, were visually compared with the reference plants of tested cultivar. Plants that served as the reference were produced from greenhouse vegetatively propagated cuttings to ensured high genetic stability and true-to-typeness. The reference plants grew in the same conditions as regenerants.

\subsection{Flow Cytometric Measurements}

The ploidy level of the studied chrysanthemum samples was estimated by flow cytometry based on genome size analysis. The 2C DNA content was analyzed in young leaves of the reference 'Profesor Jerzy' plants (propagated from cuttings in a greenhouse), control (regenerated in vitro from non-irradiated ovaries) and the regenerants originated from irradiated ovaries. The samples were prepared according to the procedure described by Jedrzejczyk and Sliwinska [31], using Galbraith's buffer $(45 \mathrm{mM} \mathrm{MgCl} 2,30 \mathrm{mM}$ sodium citrate, $20 \mathrm{mM} 3$-(N-morpholino)propanesulfonic acid and 0.1\% (v/v) TritonX-100, pH 7.0; [32]), supplemented with propidium iodide (PI $50 \mu \mathrm{g} / \mathrm{mL}$ ), ribonuclease A (RNase A $50 \mu \mathrm{g} / \mathrm{mL}$ ) and $2.0 \%(w / v)$ antioxidant polyvinylpyrrolidone (PVP-10). For each sample, the genome 
size was measured in 5000-7000 nuclei using a CyFlow Ploidy Analyser (Sysmex Partec $\mathrm{GmbH}$, Görlitz, Germany) and linear amplification. The histograms were analyzed by the CyFlow Cube program (Sysmex Partec GmbH, Görlitz, Germany). The nuclear DNA content was calculated using linear relationship between the ratio of $2 \mathrm{C}$ peak position of chrysanthemum samples and the internal standard (Vicia faba 'Inovec'; $2 \mathrm{C}=26.90 \mathrm{pg}$; [33]), on the histogram of fluorescence intensities.

\subsection{Statistical Analyses}

As for the regeneration, two-way ANOVA was performed to study the effect of genotype and irradiation treatments (type and dose). The in vitro experiment was designed as completely randomized with 10 replications, eight explants per replication, which gave 80 explants per treatment, 800 in total (two cultivars and five irradiation treatments).

Since 'Karolina' cultivar produced very few shoots in vitro, greenhouse biometrical measurements and analyses of the impact of irradiation treatments on the growth and development of greenhouse cultivated plants were performed exclusively for 'Profesor Jerzy' cultivar. All plants producing flowers in 2019 year were taken into data analysis (in total: 354). Data referring to stem length and number of days to flower (from start of the short day up to first inflorescence fully developed) were analyzed with one-way ANOVA.

Density plots for plant height and number of days to flower were created on the base of histograms for real data and fitted to normal distribution according to the common algorithm. Data expressed as share (percentage) were statistically analyzed after Freeman-Tukey's transformation, results presented in plots are the real data. The differences between means were post-hoc verified with Duncan's test at $p \leq 0.05$. Statistical analyses were performed with the application of Statistica 13.3 software package (Tibco, Palo Alto, CA, USA).

\section{Results}

\subsection{The Influence of Irradiation Dose and Type on In Vitro Regeneration from Ovaries}

There was a clear evidence of strong genotype impact on the capability to form shoots from irradiated and control ovaries in chrysanthemum. Although 'Karolina' overgrew with more abundant callus in the induction step (average 33.3\% more callus than 'Profesor Jerzy' as measured by callus diameter), it failed to produce shoots in the regeneration step (Figures 3 and 4 ).

There were totally only seven viable shoots regenerated from 'Karolina' in contrast to 'Profesor Jerzy', which produced in vitro during the same period and in the same conditions a total number of 428 shoots (Figure 4). Moreover, the first shoots of 'Profesor Jerzy' were formed as soon as in the seventh week after inoculation, actually during the induction step, while the first 'Karolina' shoot was visible as late as in the 15th week of regeneration step, it is 27 weeks after inoculation. For 'Karolina' the mean share of explants producing shoots was 2.9\%, while for 'Profesor Jerzy' it was 66.6\% (Figure 3), mean numbers of shoots regenerated from ovaries as calculated per inoculated and per regenerating explant were for 'Karolina' 0.03 and 0.18; for 'Profesor Jerzy' 1.27 and 1.80, respectively. All shoots emerged from callus formed around the ovaries. 


\section{Callus Diameter (mm)}
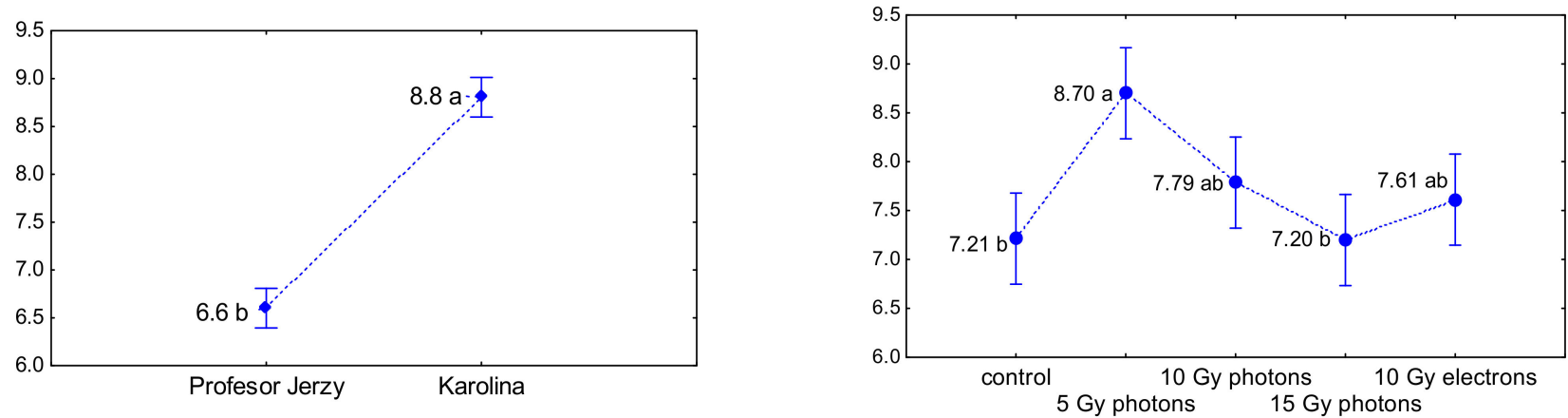

Share (\%) of Explants Regenerating Shoots
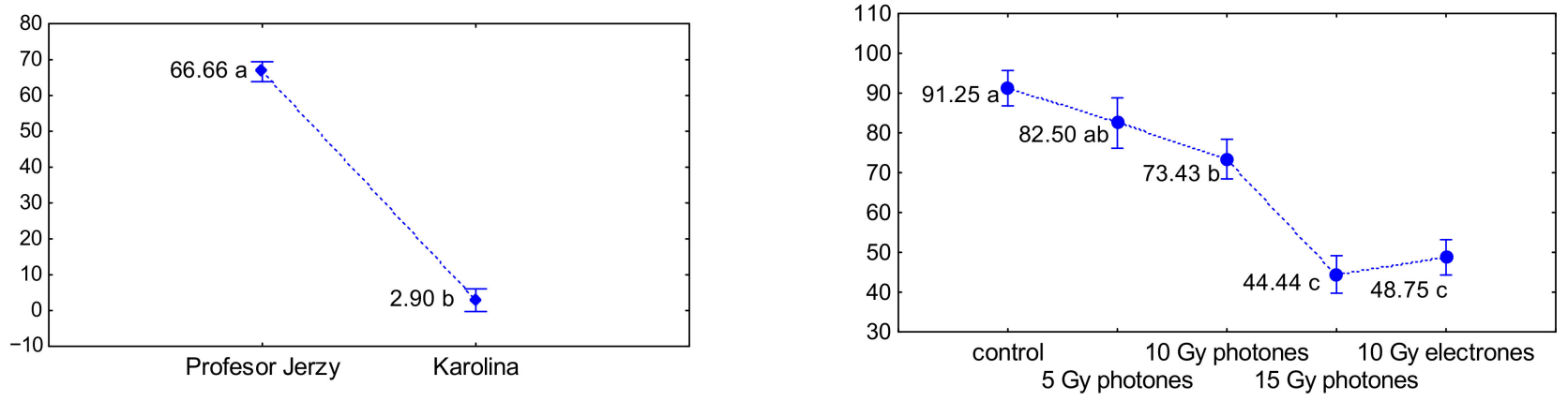

Average Number of Regenerated Shoots per Inoculated Explant
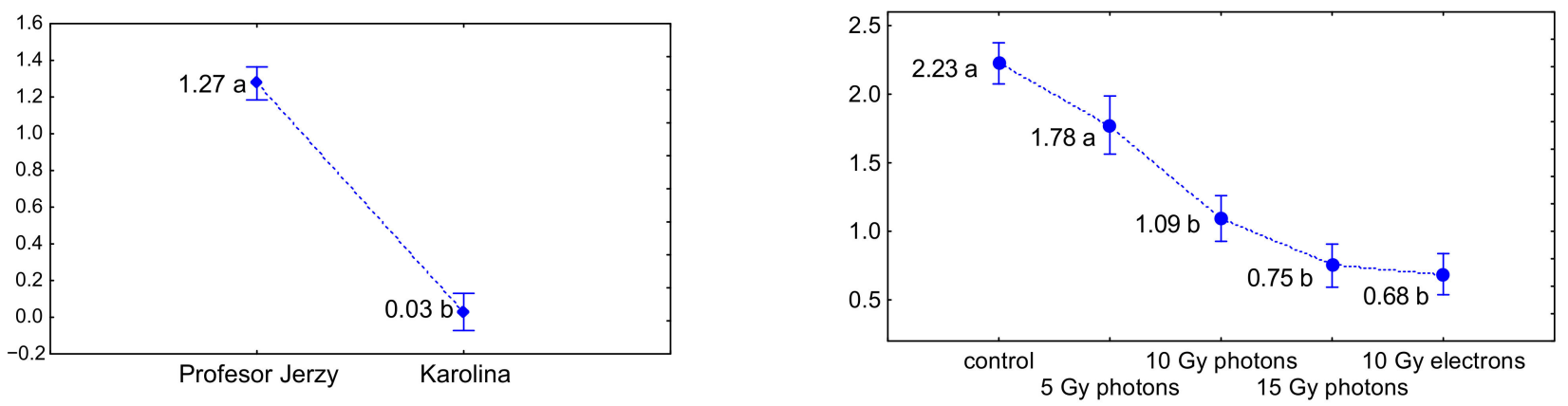

Average Number of Regenerated Shoots per Responsing Explant
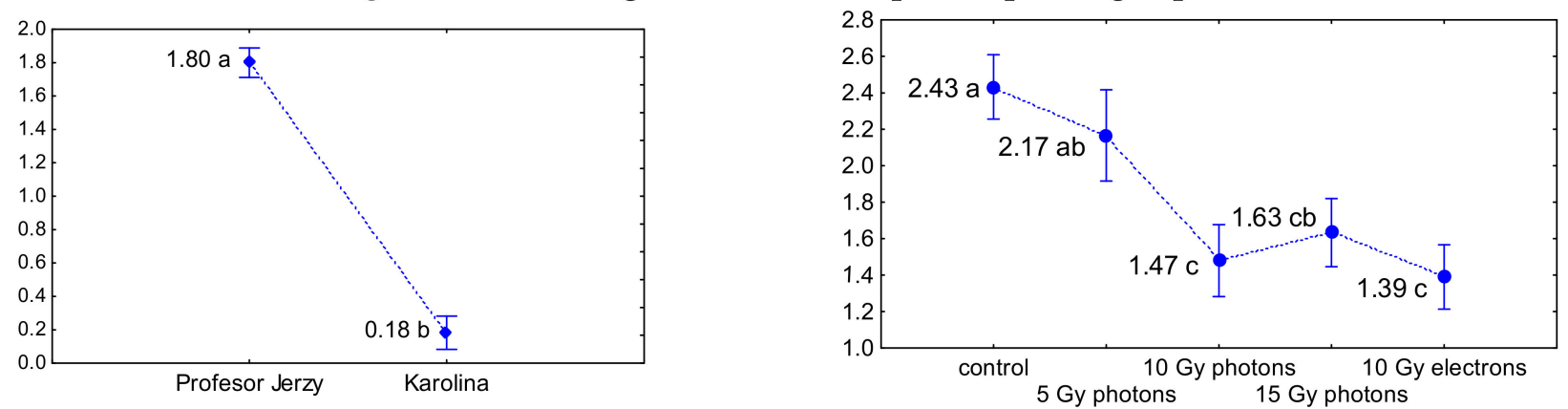

Figure 3. The effect of genotype (left plots) and dose and type of irradiation with high-energy photons and electrons (right plots) on the in vitro regeneration characteristics of chrysanthemum explants after 12 weeks of induction step (for callus diameter) followed by 18 weeks of regeneration step. In case of irradiation type and dose impact on the callus diameter it was calculated for both studied cultivars ('Profesor Jerzy' and 'Karolina') while share of explants regenerating shoots and average numbers of regenerated shoots were calculated exclusively for 'Profesor Jerzy'. Means followed by the same letter do not differ significantly at $p \leq 0.05$, whiskers indicate SE. 


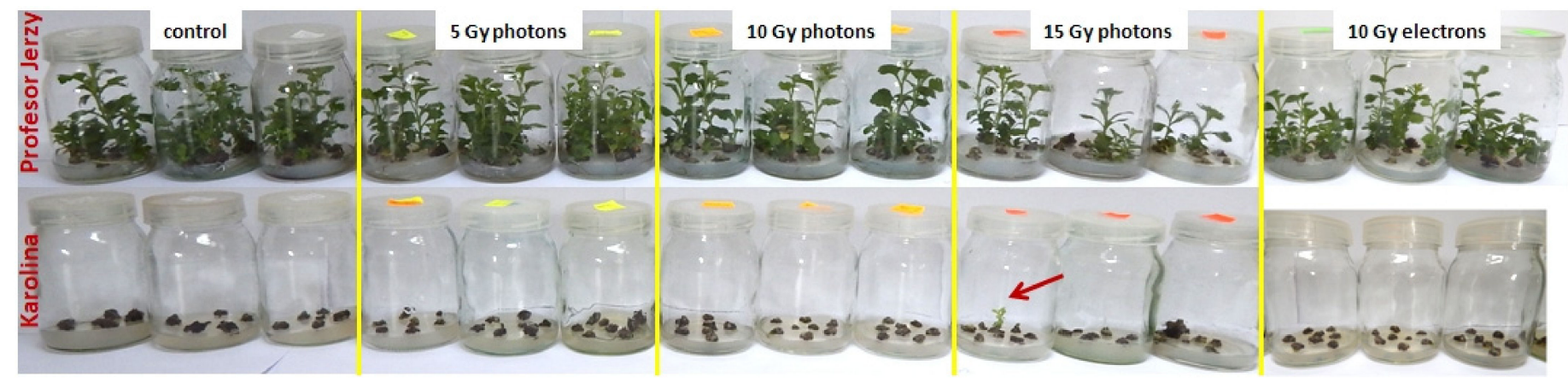

Figure 4. Explants of two cultivars with shoots regenerated after 17 weeks on the regeneration medium. Arrow indicates a single shoot in 'Karolina' culture.

Irradiation dose and type exerted profound impact on the ovaries regeneration capability. The diameter of callus formed from explants treated with 5 Gy high-energy photons was the highest $(8.7 \mathrm{~mm}$ ) and significantly different than the control and 15 Gy photons treated ovaries (in these two cases the diameter was similar, around $7.2 \mathrm{~mm}$ ) (Figure 3). This effect might be due to enhancing influence of low dose of irradiation on the process of callus regeneration. The percentage of explants regenerating shoots was adversely affected by the dose and type of irradiation (Figure 4). Non-irradiated ovaries produced shoots in $91.25 \%$, while less than half of the explants irradiated with the highest dose of high-energy photons and electrons regenerated shoots ( $44.44 \%$ and $48.75 \%$, respectively). Similarly, with an increase of dose decreased mean numbers of regenerated shoots per explant. For control explants it was 2.23 (2.43 as calculated per regenerating explant), while for $15 \mathrm{~Gy}$ photons and 10 Gy high-energy electrons it was 0.75 and 0.68 , respectively (1.63 and 1.39 , respectively, as calculated per regenerating explant) — that is several times lower than in the control (Figure 3).

Interestingly, the impact of irradiation treatments on the sterility of the explants was noticed and statistically proved (Figure 5). It can be stated, that with growing dose of irradiation, the percentage of sterile explants increased (gradually, from 55\% in $5 \mathrm{~Gy}$ photons to $70 \%$ in 15 Gy photons), and the highest (full) sterility was achieved for $10 \mathrm{~Gy}$ high-energy electrons treated ovaries (comparably with the control).

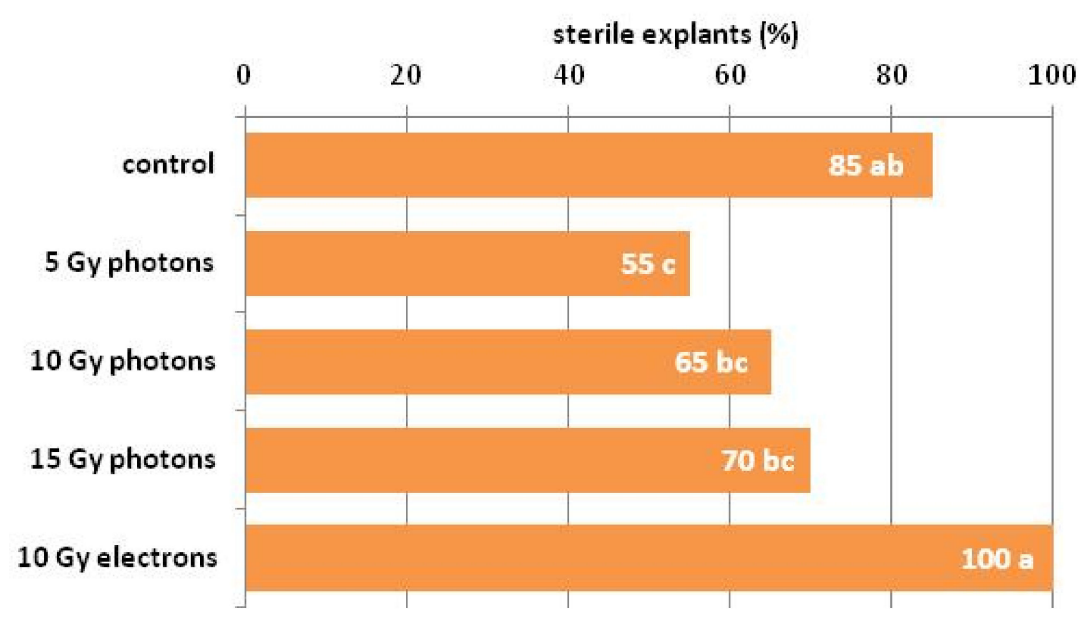

Figure 5. An effect of irradiation with different doses of high-energy photons and electrons on the share of sterile chrysanthemum explants. Data followed with the same letter do not differ significantly at $p \leq 0.05$. 


\subsection{The Influence of Irradiation Dose and Type on Greenhouse Growth and Development of Ex Vitro Derived Chrysanthemum Plants}

Due to the fact, that only a few shoots regenerated from ovaries of 'Karolina', and the shoots emerged considerably later-statistical analyses of cultivation results, phenotype observations and flow cytometry analyses were performed exclusively for 'Profesor Jerzy' cultivar.

From the total number of 428 shoots regenerated in the in vitro cultures, $89.18 \%$ were successfully acclimatized and intended for the greenhouse cultivation.

Significant impact of the irradiation on the ability to produce flowers was observed in the first year of cultivation (Figure 6). Plants originated from $15 \mathrm{~Gy}$ photons and $10 \mathrm{~Gy}$ electrons formed flowers at lowest percentage $(80.9 \%$ and $78.0 \%$, respectively), while plants originated from other treatments produced flowers between $95.1 \%$ and $100 \%$. However, this effect was diminished in the second year of cultivation-almost all plants flowered, irrespectively to the treatment.

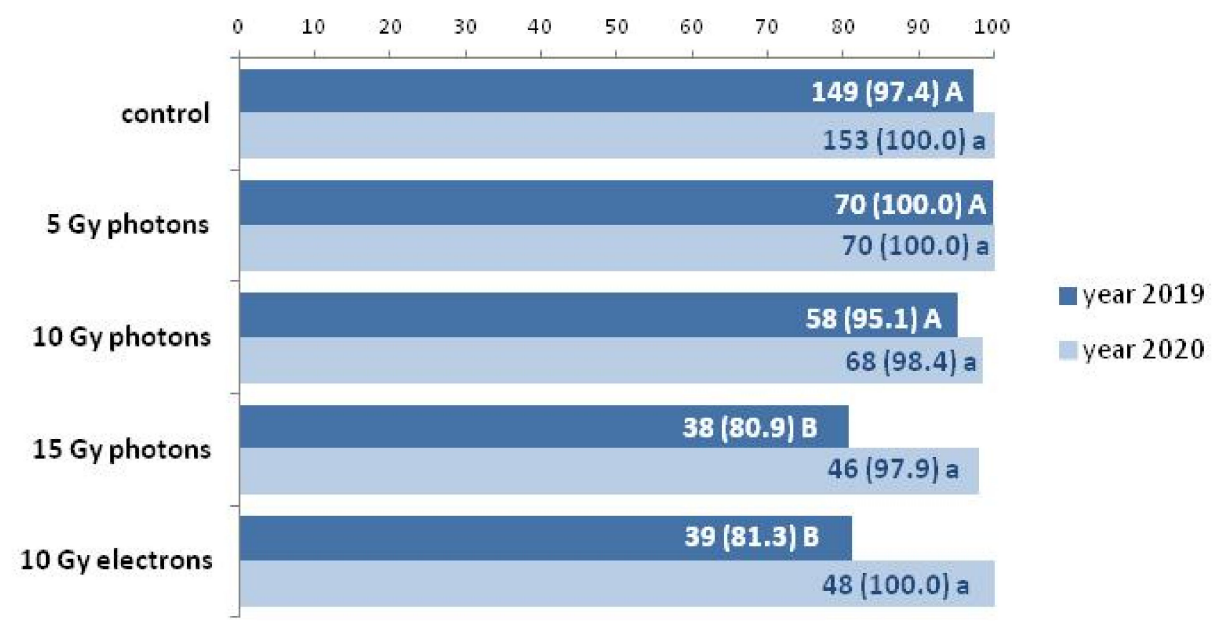

Figure 6. Number and share (\%, in brackets) of flowering chrysanthemums of 'Profesor Jerzy' in two successive years as influenced by the dose and type of irradiation applied towards ovaries from which the plants were derived. Means for each year followed by the same letter do not differ significantly at $p \leq 0.05$. Upper-case for 2019, lower-case for 2020 .

An interesting effect of enhanced growth by a low dose of irradiation was observed regarding to plant's height (Figure $7 \mathrm{~A}, \mathrm{C})$. Plants originated from ovaries irradiated with 5 Gy photons were the highest $(18.69 \mathrm{~cm}), 10 \mathrm{~Gy}$ photons plants were medium-sized $(17.25 \mathrm{~cm})$, while $15 \mathrm{~Gy}$ photons and 10 Gy electrons originated plants were the shortest (15.79 and 16.33, respectively). Moreover, as shown on the density plots, the range of plants height was broader for the latter (from 6 to $26 \mathrm{~cm}$ ) as compared to narrow plots for control and $5 \mathrm{~Gy}$ photons originated plants $(12-24 \mathrm{~cm})$. In a group of plants obtained from ovaries treated with the highest dose of photons and electrons, short plants with short internodes were observed. Their shoots often formed a kind of rosette, on which top a small inflorescence was developed. This effect was overcome in the second year of cultivation, when almost all plants produced typical shoots.

Plants obtained from explants treated with 10 Gy electrons had significantly delayed period of flowering, they were at the stage of full blooming about two days later than the other plants (Figure 7B,D). Similarly, as for plants' height, the range of days to flower in these plants was broader, from 50 to 67 , while other plants produced flowers more uniformly in time-from 52 to 64 days. 

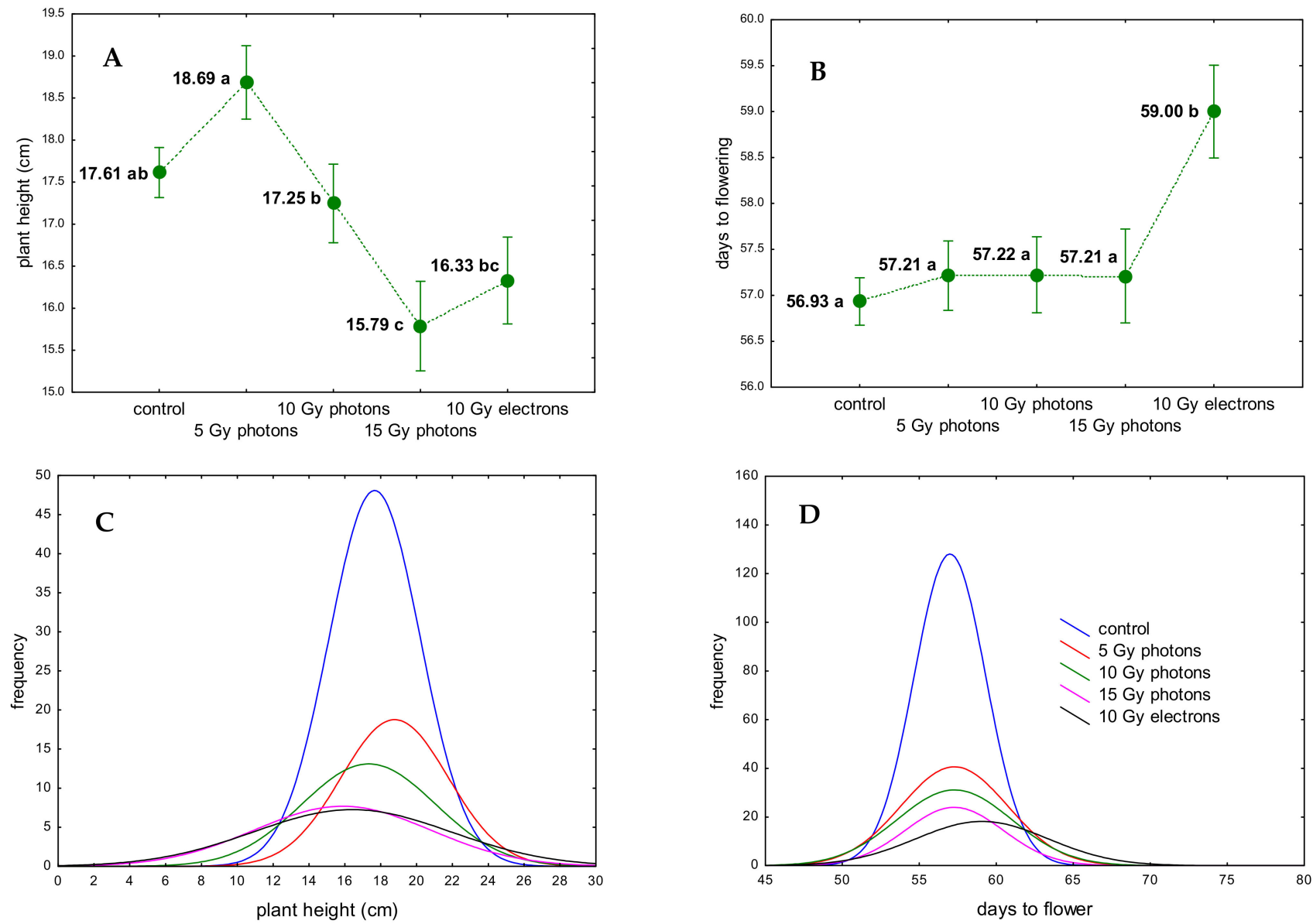

Figure 7. Effect of dose and type of irradiation with high-energy photons and electrons on subsequent in vivo growth and flowering of chrysanthemum 'Profesor Jerzy' plants originated in vitro from irradiated ovaries (first season, year 2019): plant height $(\mathrm{cm})(\mathbf{A}, \mathbf{C})$ and flowering time expressed as number of days required to full blossom (B,D). For (A,B): means followed by the same letter do not differ significantly at $p \leq 0.05$, whiskers indicate SE. For (C,D): density plots were calculated according to normal distributions on the base of real frequency of observed individuals.

Considering the impact of the irradiation treatments of explants on the phenotypical changes in plants regenerated from them, we focused on the inflorescence traits, since they are qualitative, objective and easy to be observed without any doubts. Moreover, the inflorescence appearance is at the top of the interest of ornamental plants breeders.

All reference plants, which were propagated vegetatively without in vitro phase, produced true-to-type inflorescences: full, white, with flat ligulate florets. For ex vitro regenerants three main alternations were observed: complete change of color, change of shape (predominantly to semi-full inflorescence with visible disc florets) and presence of yellow lines/sectors on white inflorescences (Figures 8 and 9). 


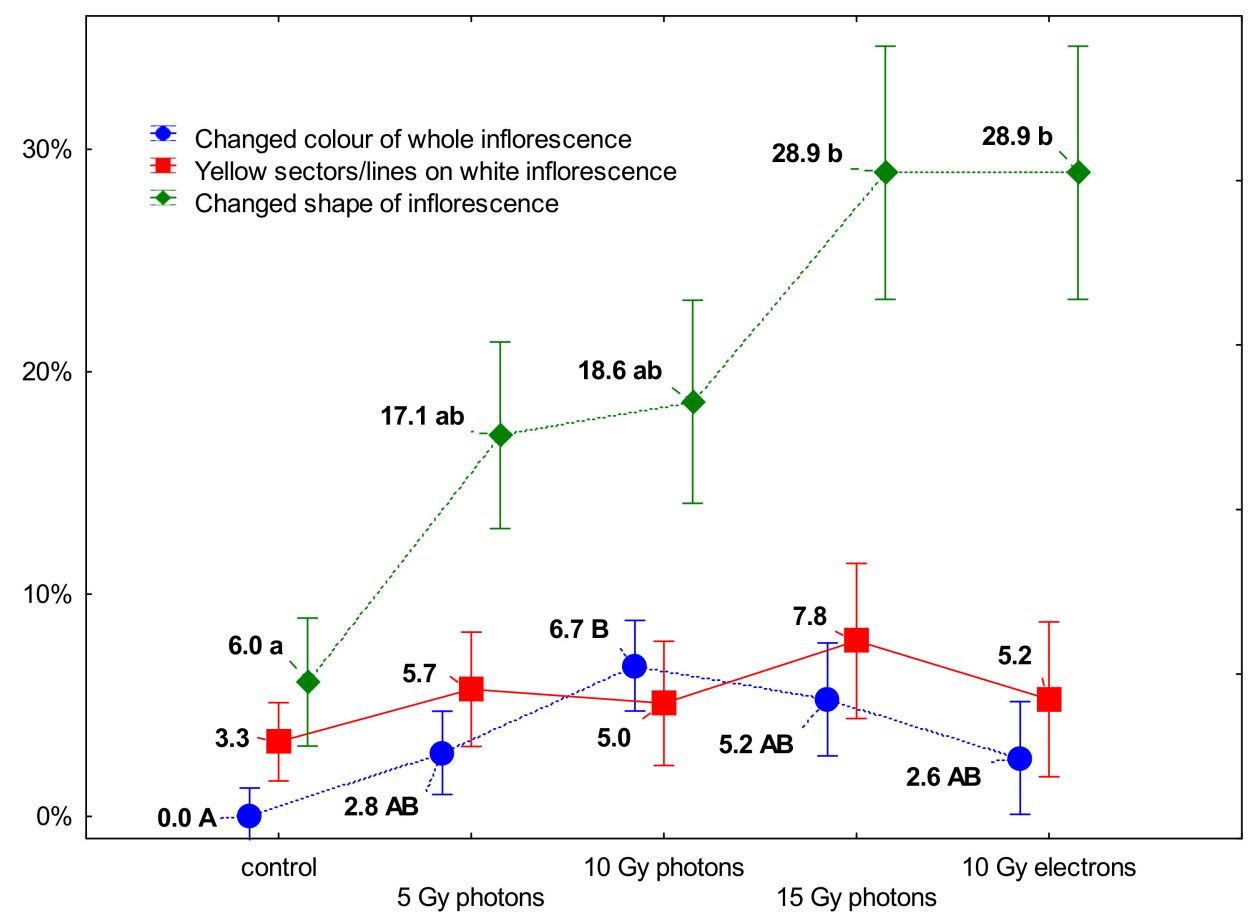

Figure 8. Frequency of variation expressed as the share (\%) of particular alternations of inflorescence traits in flowering 'Profesor Jerzy' chrysanthemum plants, originated in vitro from explants irradiated with different doses of high-energy photons and high-energy electrons. Means followed by the same letter do not differ significantly at $p \leq 0.05$ (upper-case: changed color of the whole inflorescence, lower-case: changed shape), whiskers indicate SE. Results for yellow sectors/lines on inflorescences did not differ significantly.

The share of inflorescences with shape change increased with the dose of irradiationamong control plants only $6 \%$ were of different shape, while among 15 Gy photons and 10 Gy electrons the share of shape-changed plants was $28.9 \%$. Yellow sectors or lines were observed at a mean value of 5.4 in all regenerants, irrespectively to dose and type of irradiation; none of them were present in reference plants.

Complete change of inflorescence color was observed only in plants obtained from irradiated explants and the share was the highest in 10 Gy photons originated plants. The variations of color in the tested cultivar were mainly two: yellow (in two hues) and pinkish (Figure 9). Light yellow variation was unstable and did not occur in the second year of cultivation (Table 2); plants which expressed it in the first season, produced white inflorescences in the second season. Adversely, pinkish inflorescences appeared in the second year of cultivation in four plants, which were white colored in the first one. Dark yellow color of inflorescences recurred in the second year. Moreover, its stability was confirmed in several vegetative multiplications with cuttings, which were conducted additionally to increase the number of these interesting and valuable mutants.

As considered totally, the share of not-true-to-type plants was significantly higher in plants originated form irradiated explants than from control (Figure 10). The inflorescence variations (shape and color together) predominantly recurred in the second year, except for 15 Gy photons originated plants-the recurrence was below $90 \%$ in this group.

It is worth mentioning here, that five out of seven ovary originated shoots of 'Karolina' were successfully, though later than 'Profesor Jerzy', acclimatized and in the second year of cultivation they produced flowers. Among them, four were true-to-type and one was bearing an attractive, orange-red inflorescence (regenerated from $15 \mathrm{~Gy}$ high-energy photons irradiated ovary, Figure 11). 
Table 2. Share (\%) and number (in brackets) of 'Profesor Jerzy' inflorescences representing different, non-chimerical colors depending on the irradiation treatment of original in vitro explants. Data shown for two successive years from green-house cultivation of the same plants. White color is typical for the reference inflorescence.

\begin{tabular}{|c|c|c|c|c|c|}
\hline Inflorescence Color & Control & 5 Gy Photons & 10 Gy Photons & 15 Gy Photons & 10 Gy Electrons \\
\hline \multicolumn{6}{|c|}{ Year 2019} \\
\hline White & 100 (149) & $97.1(68)$ & $93.1(54)$ & $94.7(36)$ & $97.4(38)$ \\
\hline Dark yellow & - & $2.9(2)$ & $3.4(2)$ & $2.6(1)$ & - \\
\hline Light yellow & - & - & $1.7(1)$ & $2.6(1)$ & - \\
\hline Pinkish & - & - & $1.7(1)$ & - & $2.6(1)$ \\
\hline \multicolumn{6}{|c|}{ Year 2020} \\
\hline White & $100(153)$ & $97.1(68)$ & $93.3(56)$ & $93.5(43)$ & $96.0(50)$ \\
\hline Dark yellow & - & $2.9(2)$ & $3.3(2)$ & $2.2(1)$ & - \\
\hline Light yellow & - & - & - & - & - \\
\hline Pinkish & - & - & $3.3(2)$ & $4.3(2)$ & $4.0(2)$ \\
\hline
\end{tabular}

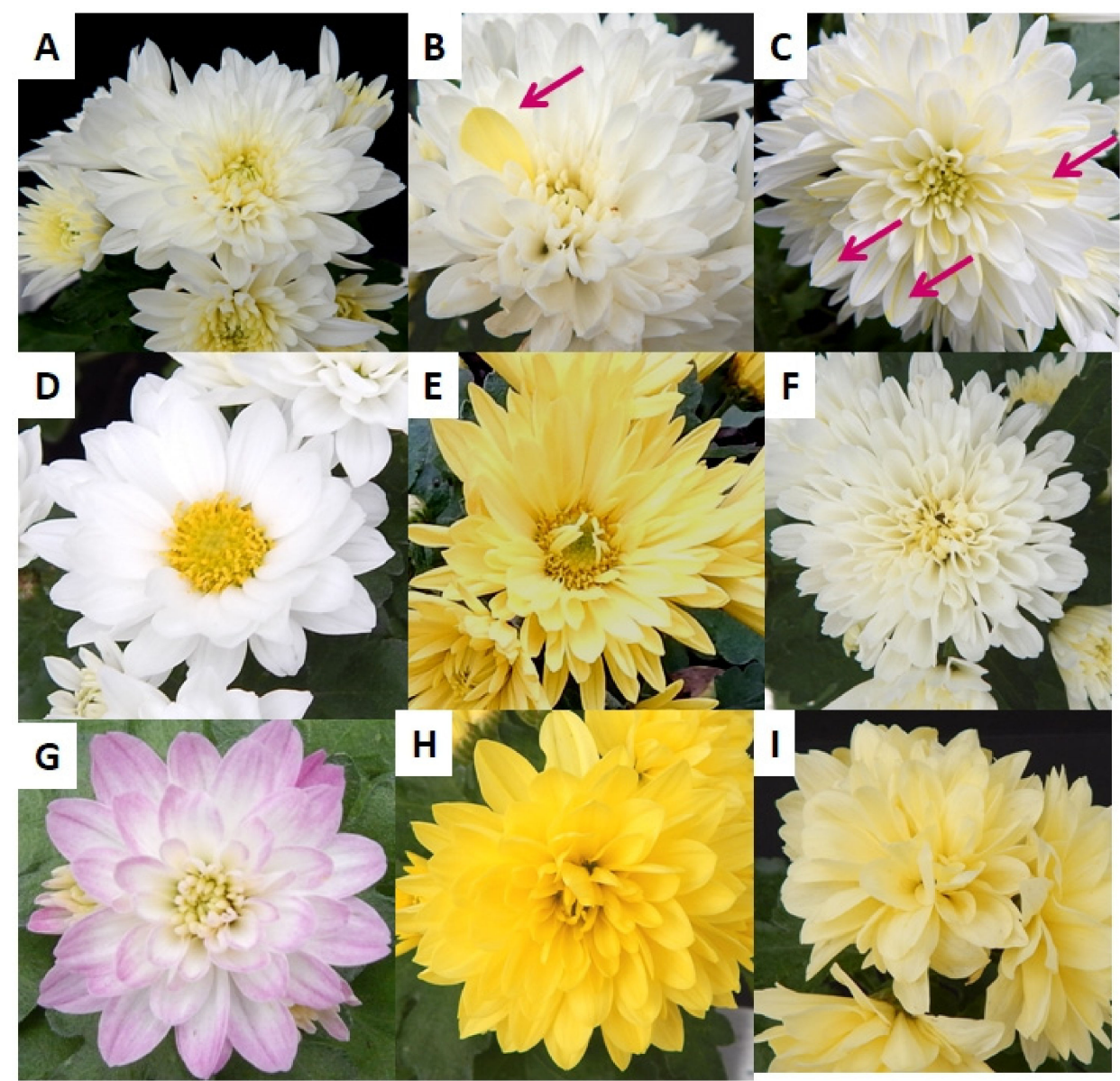

Figure 9. Types and colors of inflorescences of 'Profesor Jerzy' obtained in experiment as a result of regeneration from ovaries irradiated with high-energy photons and electrons in various doses. (A) Reference phenotype-white (155 D*), full inflorescence with open, flat ligulate florets. (B) White, full inflorescence with light yellow sector (arrow). (C) White, full inflorescence with multiple yellow lines on ligulate florets (arrows). (D) White, semi-full inflorescence. (E) Light yellow (4 C), semi-full inflorescence. (F) White (155 D), full inflorescence with ligulate florets grown in tubes with ragged endings. (G) Pinkish (69 D), full inflorescence. (H) Dark yellow (RHSCC: 5 A), full inflorescence. (I) Light yellow (4 C), full inflorescence. ${ }^{*}$ Color codes were indicated with the Royal Horticultural Society Color Chart. 

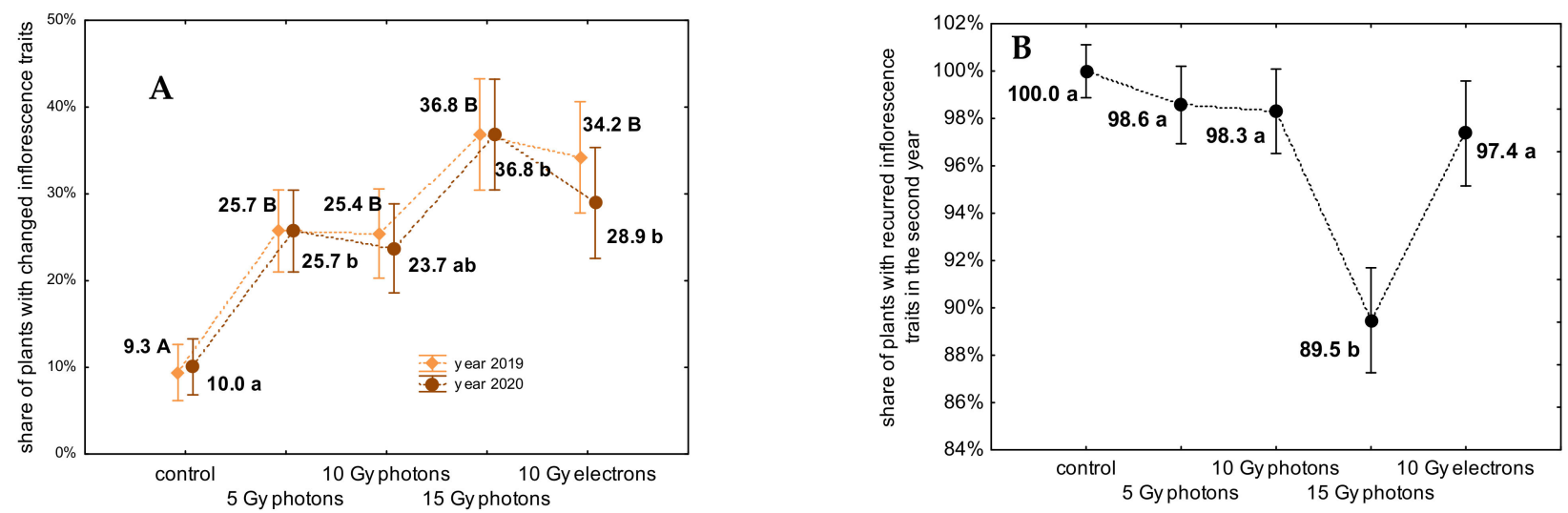

Figure 10. (A): Frequency of variation as an effect of irradiation with high energy-photons and high-energy electrons on the total share (\%) of 'Profesor Jerzy' plants with changed inflorescence traits (color or shape) in two successive years. Means followed by the same letter do not differ significantly $p \leq 0.05$ (upper-case for 2019, lower-case for 2020), whiskers indicate SE. (B): The recurrence of the inflorescences traits in the second year of cultivation expressed as the share (\%) of plants flowering both in 2019 and 2020, which recurred their inflorescence traits (color and shape). Means followed by the same letter do not differ significantly at $p \leq 0.05$, whiskers indicate SE.

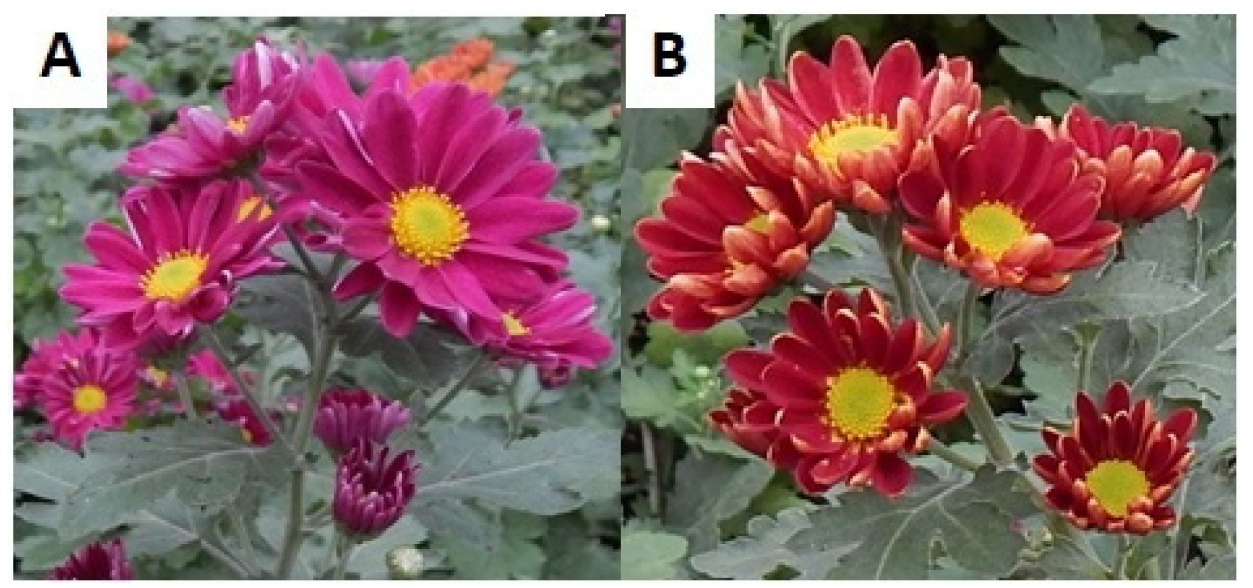

Figure 11. 'Karolina' reference phenotype (A): semifull, flat ligulate florets, purple color (71 B *), and the sole mutant obtained after treatment with $15 \mathrm{~Gy}$ high-energy photons (B): semifull, curved ligulate florets, orange-red color (42 B). ${ }^{*}$ Color codes were indicated with the Royal Horticultural Society Color Chart.

\subsection{C DNA Results}

The mean genome size obtained for the hexaploid reference Chrysanthemum $\times$ morifolium 'Profesor Jerzy' was $17.74 \mathrm{pg} / 2 \mathrm{C}$, for the control plants amounted $17.77 \mathrm{pg} / 2 \mathrm{C}$, whereas from irradiated plant material ranged between 16.78 and $17.46 \mathrm{pg} / 2 \mathrm{C}$ DNA content indicating that they were also hexaploids (Figure 12). Thus, it can be concluded that regeneration of shoots was induced from somatic tissues of ovaries, most probably the ovary wall, not from the ovule constituents. 


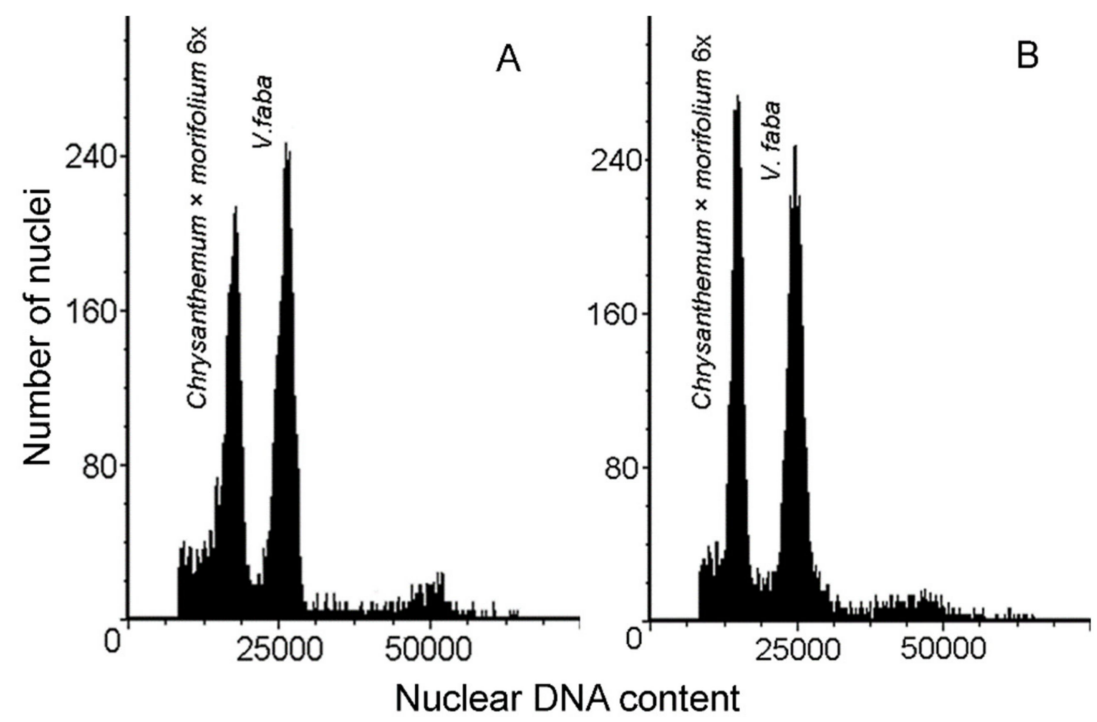

Figure 12. Selected histograms of the nuclear DNA content obtained after flow cytometric analysis of chrysanthemum plants and internal standard of Vicia faba; (A): reference of Chrysanthemum $\times$ morifolium 'Profesor Jerzy' and (B): an example of regenerant derived from 10 Gy high-energy electrons treated ovary.

\section{Discussion}

Most contemporarily cultivated Chrysanthemum $\times$ morifolium cultivars possess $2 n=6 x=54$ chromosomes [5], so did 'Profesor Jerzy', both cultivated in green-house from cuttings (reference plants) and regenerated from ovaries. This shows, that no regeneration from ovule sac underwent, and no haploid plants were created, as revealed by flow cytometric analysis - the most reliable method of quick ploidy/genome size estimation [34]. In the two-step protocol applied in this current study, regenerants were originated with the highest probability from somatic tissues of ovary wall that first formed callus from which shoots arose. It was confirmed by our observations-we still found intact ovules overgrown with callus in 12 week-old ovary explants (unpublished data). Throughout all of the years and numerous attempts made by various scientists $[27,28]$, there had not been elaborated an efficient protocol for the routine regeneration of haploid plants in chrysanthemum, unlike for the other species, both by gyno- and androgenesis [35].

In case of our approach, although ovaries did not produce haploids (which was not the intention here), they served as convenient irradiation objects. Their placement in an inflorescence, gathering plenty of them in one plane, and good regeneration potential are the attitudes of ovaries as explants used for mutation breeding purposes in chrysanthemum. The small size of an ovary, and the regeneration from thin layer of tissue wrapping ovule, resemble the concept of thin cell layer (TCL) culture [36]. In principal, TCL explant is under $2 \mathrm{~mm}$ in thickness and, due to its enhanced regeneration capacity evoked by plant growth regulators, and freeing from the impact of donor plant, it can easily be managed to regenerate in desired directions [37].

In vitro regeneration of shoots from non-meristemic explants as a method to obtain non-chimerical mutants in chrysanthemums was first announced by Broertjes and coworkers in the late 70s [21]. The technique has proven its applicability for many other species and is nowadays widely used in practical breeding [38]. Numerous studies show various response of cultivars to regeneration from non-meristemic explants-from abundant to poor $[9,19,23,24]$. Leaves, internodes and less frequently-receptacles or ligulate florets are the common explants applied in the approach [23,39-41]. Nobody has used ovaries for mutation breeding before, both in chrysanthemum and in other species.

We succeeded with the formation of novel traits of inflorescences after irradiation, meanwhile some chimera plants possessing yellow sectors on white inflorescences ap- 
peared in the group of plants regenerated from ovaries, irrespectively to irradiation treatment. At the same time, yellow sectors were not present in the reference plants propagated with cuttings. Sectorial chimeras in chrysanthemum result from a partial mutation of a meristem [42]. In our study this phenomenon can be explained with generally higher mutability of ovary-derived plants, nonetheless it requires further investigations.

The success of classical mutation breeding is defined by a high number of new, desired forms of the cultivar originated from a relatively small number of mother plants or explants. As reviewed by Jo and Kim [3], the frequency of variations depends on many factors, among them linear energy transfer (LET), irradiation type and dose, and type of irradiated tissue are the most influential. In our study, the dose and type of irradiation exerted a pleiotropic effect on plants. Irradiation treatments affected in vitro regeneration efficiency, flowering ability and date, plant height retardation and stable change of inflorescence shape and color. According to studies performed in the field of medical sciences, the effects of radiation in living organisms can be classified as deterministic and stochastic [43]. In our study, we observed mostly stochastic effects, which are correlated with the dose increase, e.g., gradual decrease in regeneration capacity, retardation effect on stem length and increased share of semifull inflorescences. The inflorescence color change was evoked by all doses of high-energy photons and electrons, but the significantly higher share of color change was present in 10 Gy photons originated plants. This may suggest a presence of specific threshold of the dose, above which the mutation frequency does not increase, and is typical for deterministic effects.

An example of temporary effect of irradiation was the partial disability of plants to produce flowers in the first year of cultivation. This influence erased in the second year of cultivation and could be an effect of epigenetic factors [44]. The fact, that this effect was induced several months before, in irradiated ovary tissues, and was transmitted through in vitro culture phase and further greenhouse growth, is particularly interesting. The transition ability of epigenetic changes through in vitro culture to in vivo conditions was detected in Doritaenopsis [45].

Another unstable effect was the presence/absence of light yellow and pinkish inflorescences. The lowest recurrence of this trait was observed in $15 \mathrm{~Gy}$ high-energy photons originated plants. Color of inflorescences in chrysanthemums is determined by the presence of anthocyanins and carotenoids in (mainly) ligulate florets [46]. Florets are formed with two histogenic layers: L1 and L2. Anthocyanins expression occurs in L1 exclusively, while carotenoids can be observed in either one or both layers [47]. It can be assumed, that light yellow color of inflorescence was unstable, since plants bearing it were periclinal chimeras, with carotenoids only in one layer of florets. Such chimeras possess usually stable phenotypes, repeating their pattern via vegetative propagation [48]. However, in our experiment branching in the second year of cultivation resulted in the loss of the light yellow phenotype. It can be concluded that probably unmutated tissues had dominated the mutated ones in lateral meristems, leading to their extinction [20]. The instability of pinkish inflorescences is much harder to explain, since they appear and disappear in both years of cultivation, this trait requires more observations in following vegetative generations. However, an unstable, specific DNA-methylation pattern could be a possible explanation [44].

The goal of high frequency of variation can be achieved only in case many favor factors meet together to respond the need. Among these factors, highly responsible for the guarantee of success are the genotype of the mother plant and its regeneration capability [49]. Throughout many years of practical experiments in mutation breeding it has been proved, that the greatest number of color mutants arise from mother plants with purple violet inflorescences, which can mutate to form white, yellow, red, brown and orange inflorescences of different hues [2]. Nonetheless, to reveal the potential of color mutations of mother genotype, the plant must proliferate following the mutagenic treatment. In our study, one cultivar-'Karolina', having a promising potency for color change, failed to regenerate. Nonetheless, among only few (namely: seven) shoots produced from irradiated 
ovaries, one appeared to be an attractive color mutant. On the contrary, the second cultivar 'Profesor Jerzy' showed excellent regeneration performance, however the inflorescence color variations were few, which is in line with the reported potency of white cultivars for color change [2]. The results encourage to develop the protocol of regeneration from ovaries for cultivars potentially attractive as mother plants, but reluctant to regeneration.

Regeneration capacity in our experiment was negatively correlated with the dose and type of irradiation: the higher the radiation dose, the lower the regeneration efficiency. A similar effect was observed in the experiments carried out with ion beams ( $0-40 \mathrm{~Gy})$ and gamma rays (15-60 Gy) applied on chrysanthemum leaf explants; with a total dose increase the regeneration decreased [11,50]. However, it was found in rice that the lower the survival rate after irradiation treatment, the higher the mutation frequency [51]. It is in line with our results: with the decrease of regeneration capacity, the variation frequency increased. We observed the highest variation frequency in plants regenerated from $10 \mathrm{~Gy}$ high-energy electrons and 15 Gy high-energy photons treated ovaries-both reduced the share of explants regenerating shoots by half showing total variation frequency at $36.8 \%$ and $34.2 \%$, respectively.

In our study, there was a considerable prolongation of inflorescence bud development in 15 Gy high-energy photons and 10 Gy high-energy electrons originated plants. In somaclones of three chrysanthemum cultivars obtained from protoplast regeneration, it was observed a delay in a retention time (number of days between the start of the short day and the presence of fully developed inflorescence) in some of the individuals [52]. In terms of floricultural practice, longer period of inflorescences development is disadvantageous, since the costs of yield production increase. Unfortunately, mutations either induced or spontaneous, often lead to unfavorable changes.

Interestingly, the effects of $10 \mathrm{~Gy}$ high-energy electrons were stronger in case of parameters such as decrease in regeneration capacity, stem length retardation, flowering delay and flowering disability, in comparison to the effects of $10 \mathrm{~Gy}$ high-energy photons, and similar to $15 \mathrm{~Gy}$ high-energy photons. The nature of action of high-energy electrons is physically different than high-energy photons [53].

High-energy photons are highly penetrating, they do not possess a charge, and are responsible for indirect ionization of the matter, while high-energy electrons are less penetrative than photons and they produce much denser ionization within matter, since they possess a charge $[17,18]$. Although the irradiation treatments were asset to the same beam energy of all treatments, due to different way of action in tissues the effects are different for different types of irradiation. The high-energy electrons, although they exerted a significant impact on the regeneration and flowering time, did not increase the probability of novel stable color mutants creation. In previous studies performed by Yamaguchi and coworkers [11] the application of charged particles for mutagenic treatments, i.e., carbon and helium ion beams at much higher beam energy than in the present study $(100-320 \mathrm{MeV})$, resulted in higher frequency of flower color mutations in chrysanthemum as compared to gamma rays. There has not been any research on the application of high-energy electrons in induced mutagenesis in chrysanthemum since now. The efficient deployment of this type of irradiation in mutation breeding needs to be developed.

Additional side effect of the irradiation with different doses and types of radiation was the effect of sterilization enhancement. Since ovaries are ex vivo taken explants, they need surface disinfection prior to culture initialization. The manipulation of irradiated inflorescences, loading them with plastic clay, transportation to the place of irradiation caused lower sterility of explants as compared to directly taken, non-irradiated ovaries. The exception were explants treated with high-energy electrons, which showed $100 \%$ of sterility. One of the applications of ionizing radiation is the process of industrial sterilization, in which high-energy photons and high-energy electrons are commonly deployed [17]. Highenergy photons have better matter penetration ability than electrons, although the latter exert stronger effect with direct ionization. In our studies high-energy electrons enhanced the disinfection effect more than high-energy photons. 


\section{Conclusions}

Irradiation of the whole intact inflorescences and further utilization of ovaries excised from them as explants in classical mutation breeding can be efficiently used for chrysanthemum, provided good regeneration response of the mother cultivar. The advantages of this method are: (a) high amount simultaneously irradiated explants due to ovaries location within inflorescence, (b) high of in vitro regeneration efficiency in responsive cultivars and (c) satisfactory frequency of stable color and shape mutants. For irradiation treatments we recommend high-energy photons of the total dose delivered at $10 \mathrm{~Gy}$ (beam energy at $6 \mathrm{MeV}$, dose rate at $3.19 \mathrm{~Gy} \mathrm{~min}^{-1}$ ), which were the most effective in the induction of stable inflorescence color and shape mutations, without undesirable side effects like retardation or prolongation of cultivation time due to later flowering.

Elaboration of regeneration protocols from ovaries for other members of Asteraceae family will contribute in wider application of this approach in commercial plant breeding and enriching the pool of novel, attractive ornamental cultivars.

\section{Patents}

As a result of these research, two new Chrysanthemum $\times$ morifolium (Ramat.) cultivars were submitted to plant breeders' rights (PBR) at the Community Plant Variety Office (CPVO) in Poland, so far.

The first cultivar, denominated as 'UTP Bydgoska Nostalgia' was granted with PBR on 8 March 2021, registered at the application number O O2063. The cultivar is inflorescence shape mutant obtained from control ovaries, with ligulate florets grown into tubes with torn endings.

The second cultivar, referenced by breeder as UTP Jerzy mutant 12, was submitted for distinctness, stability and uniformity (DUS) tests, the application is being proceeded. The cultivar is dark yellow mutant with incurved ligulate florets, obtained from 15 Gy high-energy photons irradiated ovaries.

Author Contributions: Conceptualization, N.M., I.J. and J.W.; methodology, software, validation, formal analysis, investigation, resources and data curation: N.M., I.J., S.J. and J.W., writing—original draft preparation, N.M.; writing-review and editing, N.M., I.J., J.W.; visualization, N.M. and I.J.; supervision, N.M.; project administration, N.M. All authors have read and agreed to the published version of the manuscript.

Funding: This research received no external funding.

Institutional Review Board Statement: Not applicable.

Informed Consent Statement: Not applicable.

Data Availability Statement: Data available by e-mail on reasonable request.

Conflicts of Interest: The authors declare no conflict of interest.

\section{References}

1. Holme, I.B.; Gregersen, P.L.; Brinch-Pedersen, H. Induced Genetic Variation in Crop Plants by Random or Targeted Mutagenesis: Convergence and Differences. Front Plant Sci. 2019, 10, 1468. [CrossRef] [PubMed]

2. Datta, S.K. Induced mutations: Technological advancement for development of new ornamental varieties. Nucleus 2020, 63, 119-129. [CrossRef]

3. Jo, Y.D.; Kim, J.-B. Frequency and Spectrum of Radiation-Induced Mutations Revealed by Whole-Genome Sequencing Analyses of Plants. Quantum Beam Sci. 2019, 3, 7. [CrossRef]

4. Shelake, R.M.; Pramanik, D.; Kim, J.Y. Evolution of plant mutagenesis tools: A shifting paradigm from random to targeted genome editing. Plant Biotechnol. Rep. 2019, 13, 423-445. [CrossRef]

5. Spaargaren, J.; Van Geest, G. Chrysanthemum. In Ornamental Crops, Handbook of Plant Breeding; Van Huylenbroeck, J., Ed.; Springer: Berlin/Heidelberg, Germany, 2018; Volume 11, pp. 319-348.

6. Community Plant Variety Office (CPVO). Online Database for Registered Cultivars. Available online: https: / / cpvo.europa.eu / en/applications-and-examinations/cpvo-variety-finder (accessed on 22 May 2021). 
7. Protocol for Distinctness, Uniformity and Stability Test for Chrysanthemum $\times$ morifolium (Ramat.), Community Plant Variety Office (CPVO). 2008. Available online: https:/ / cpvo.europa.eu/sites/default/files/documents/chrysanthemum_2.pdf (accessed on 22 May 2021).

8. Kulus, D. Selected aspects of ornamental plants micropropagation in Poland and worldwide. Life Sci. 2015, 4, 1. [CrossRef]

9. Latado, R.R.; Adames, A.H.; Neto, A.T. In vitro Mutation of Chrysanthemum (Dendranthema grandiflora Tzvelev) with Ethylmethanesulphonate (EMS) in Immature Floral Pedicels. Plant Cell Tiss. Organ Cult. 2004, 77, 103-106. [CrossRef]

10. Zhao, M.-X.; Sun, H.-Y.; Ji, R.-R.; Hu, X.-H.; Sui, J.-M.; Qiao, L.-X.; Chen, J.; Wang, J.-S. In vitro mutagenesis and directed screening for salt-tolerant mutants in peanut. Euphytica 2013, 193, 89-99. [CrossRef]

11. Yamaguchi, H.; Shimizu, A.; Hase, Y.; Tanaka, A.; Shikazono, N.; Degi, K.; Morishita, T. Effects of ion beam irradiation on mutation induction and nuclear DNA content in chrysanthemum. Breed. Sci. 2010, 60, 398-404. [CrossRef]

12. Ulukapi, K.; Ozmen, S.F. Study of the effect of irradiation (60Co) on M1 plants of common bean (Phaseolus vulgaris L.) cultivars and determined of proper doses for mutation breeding. J. Rad. Res. App. Sci. 2018, 11, 157-161. [CrossRef]

13. Ibrahim, R.; Ahmad, Z.; Salleh, S.; Hassan, A.A.; Ariffin, S. Mutation Breeding in Ornamentals. In Ornamental Crops. Handbook of Plant Breeding; Van Huylenbroeck, J., Ed.; Springer: Dordrecht, The Netherlands, 2018; pp. 175-211. [CrossRef]

14. Miler, N.; Kulus, D. Microwave treatment can induce chrysanthemum phenotypic and genetic changes. Sci. Hortic. 2018, 227, 223-233. [CrossRef]

15. Slater, J.M. From X-rays to Ion Beams: A Short History of Radiation Therapy. In Ion Beam Therapy. Biological and Medical Physics, Biomedical Engineering; Linz, U., Ed.; Springer: Berlin/Heidelberg, Germany, 2012; pp. 3-13. [CrossRef]

16. Kokurewicz, K.; Brunetti, E.; Welsh, G.H.; Wiggins, S.M.; Boyd, M.; Sorensen, A.; Chalmers, A.J.; Schettino, G.; Subiel, A.; Desrosiers, C.; et al. Focused very high-energy electron beams as a novel radiotherapy modality for producing high-dose volumetric elements. Sci. Rep. 2019, 9, 10837. [CrossRef] [PubMed]

17. Parsons, B.J. Sterilisation procedures for tissue allografts. In Standardisation in Cell and Tissue Engineering; Woodhead Publishing Series in Biomaterials; Salih, V., Ed.; Woodhead Publishing: Cambridge, UK, 2013; pp. 197-211. [CrossRef]

18. Gerbi, B.J. Clinical Applications of High-Energy Electrons. In Technical Basis of Radiation Therapy. Medical Radiology (Radiation Oncology); Levitt, S.H., Purdy, J.A., Eds.; Springer: Berlin/Heidelberg, Germany, 2006; pp. 135-164. [CrossRef]

19. Kaul, A.; Kumar, S.; Ghani, M. In vitro mutagenesis and detection of variability among radiomutants of chrysanthemum using RAPD. Adv. Hortic. Sci. 2011, 25, 106-111.

20. Van Harten, A.M. Mutation Breeding. Theory and Practical Applications; Cambridge University Press: Cambridge, UK, 1998 ; p. 353.

21. Broertjes, C.; Roest, S.; Bokelmann, G.S. Mutation breeding of Chrysanthemum morifolium Ram. using in vivo and in vitro adventitious bud techniques. Euphytica 1976, 25, 11-19. [CrossRef]

22. Cassells, A.C. Tissue Culture for Ornamental Breeding. In Breeding for Ornamentals: Classical and Molecular Approaches; Vainstein, A., Ed.; Springer: Dordrecht, The Netherlands, 2002; pp. 139-153. [CrossRef]

23. Da Silva, J.A.T.; Lema-Rumińska, J.; Tymoszuk, A.; Kulpa, D. Regeneration from chrysanthemum flowers: A review. Acta Physiol. Plant. 2015, 37, 36. [CrossRef]

24. Kang, E.; Lee, Y.; Sung, S.; Ha, B.; Kim, S.; Kim, D.; Kim, J.; Kang, S. Analysis of the genetic relationship of gamma-irradiated in vitro mutants derived from standard-type chrysanthemum cv. Migok. Hortic. Environ. Biotechnol. 2013, 54, 76-81. [CrossRef]

25. Sun, C.-Q.; Chen, F.-D.; Teng, N.-J.; Liu, Z.-L.; Fang, W.-M.; Hou, X.-L. Factors affecting seed set in the crosses between Dendranthema grandiflorum (Ramat.) Kitamura and its wild species. Euphytica 2010, 171, 181-192. [CrossRef]

26. Bohanec, B. Doubled Haploids via Gynogenesis. In Advances in Haploid Production in Higher Plants; Touraev, A., Forster, B.P., Jain, S.M., Eds.; Springer: Dordrecht, The Netherlands, 2009; pp. 35-46. [CrossRef]

27. Wang, H.; Dong, B.; Jiang, J.; Fang, W.; Guan, Z.; Liao, Y.; Chen, S.; Chen, F. Characterization of in vitro haploid and doubled haploid Chrysanthemum morifolium plants via unfertilized ovule culture for phenotypical traits and DNA methylation pattern. Front. Plant Sci. 2014, 5, 738. [CrossRef]

28. Miler, N.; Muszczyk, P. Regeneration of callus and shoots from the ovules and ovaries of chrysanthemum in vitro. Acta Hortic. 2015, 1083, 103-106. [CrossRef]

29. Miler, N.; Jedrzejczyk, I. Chrysanthemum plants regenerated from ovaries: A study on genetic and phenotypic variation. Turk. J. Bot. 2018, 42, 289-297.

30. Murashige, T.; Skoog, F. A revised medium for rapid growth and bio assays with tobacco tissue cultures. Physiol. Plant 1962, 15, 473-497. [CrossRef]

31. Jedrzejczyk, I.; Sliwinska, E. Leaves and seeds as materials for flowcytometric estimation of the genome size of 11 Rosaceae woody species containing DNA-staining inhibitors. J. Bot. 2010, 2010, 930895.

32. Galbraith, D.W.; Harkins, K.R.; Maddox, J.M.; Ayres, N.M.; Sharma, D.P.; Firoozabady, E. Rapid flow cytometric analysis of the cell cycle in intact plant tissues. Science 1983, 220, 1049-1051. [CrossRef] [PubMed]

33. Dolezel, J.; Sgorbati, S.; Lucretti, S. Comparison of three DNA fluorochromes for flow cytometric estimation of nuclear DNA content in plants. Physiol. Plant. 1992, 85, 625-631. [CrossRef]

34. Sliwinska, E. Flow cytometry-A modern method for exploring genome size and nuclear DNA synthesis in horticultural and medicinal plant species. Folia Hortic. 2018, 30, 103-128. [CrossRef]

35. Dwivedi, S.L.; Britt, A.B.; Tripathi, L.; Sharma, S.; Upadhyaya, H.D.; Ortiz, R. Haploids: Constraints and opportunities in plant breeding. Biotechnol Adv. 2015, 33, 812-829. [CrossRef] 
36. Da Silva, J.A.T.; Dobránszki, J. Dissecting the Concept of the Thin Cell Layer: Theoretical Basis and Practical Application of the Plant Growth Correction Factor to Apple, Cymbidium and Chrysanthemum. J. Plant Growth Regul. 2014, 33, 881-895. [CrossRef]

37. Da Silva, J.A.T.; Fukai, S. Chrysanthemum Organogenesis Through Thin Cell Layer Technology and Plant Growth Regulator Control. Asian J. Plant Sci. 2003, 2, 505-514. [CrossRef]

38. Jain, M.S. Mutation-assisted breeding for improving ornamental plants. Acta Hortic. 2006, 714, 85-98. [CrossRef]

39. Datta, S.K.; Misra, P.; Mandal, A.K.A.; Chakrabarty, D. Direct shoot organogenesis from different explants of chrysanthemum, marigold, and tuberose. Israel J. Plant Sci. 2002, 50, 287-291. [CrossRef]

40. Miler, N.; Zalewska, M. Somaclonal variation of chrysanthemum propagated in vitro from different explant types. Acta Sci. Pol. Hortorum Cultus 2014, 13, 69-82.

41. Da Silva, J.A.T.; Kulus, D. Chrysanthemum biotechnology: Discoveries from the recent literature. Folia Hortic. 2014, 26 , 67-77. [CrossRef]

42. Chakrabarty, D.; Datta, S.K. Management of chimera and in vitro mutagenesis for development of new flower colour/shape and chlorophyll variegated mutants in chrysanthemum. In Floriculture: Role of Tissue Culture and Molecular Techniques; Datta, S.K., Chakrabarty, D., Eds.; Pointer Publishers: Jaipur, India, 2010; pp. 157-164.

43. Chang, D.S.; Lasley, F.D.; Das, I.J.; Mendonca, M.S.; Dynlacht, J.R. Stochastic, Deterministic, and Heritable Effects (and Some Radiation Protection Basics). In Basic Radiotherapy Physics and Biology; Chang, D.S., Lasley, F.D., Das, I.J., Mendonca, M.S., Dynlacht, J.R., Eds.; Springer Science+Business Media: New York, NY, USA, 2021; pp. 337-348. [CrossRef]

44. Valledor, L.; Hasbun, R.; Meijón, M.; Rodríguez, J.L.; Santamaría, E.; Viejo, M.; Berdasco, M.; Feito, I.; Fraga, M.F.; Canal, M.J.; et al. Involvement of DNA methylation in tree development and micropropagation. Plant Cell Tissue Organ Cult. 2007, 91, 75-86. [CrossRef]

45. Park, S.Y.; Murthy, H.N.; Chakrabarthy, D.; Paek, K.Y. Detection of epigenetic variation in tissue-culture-derived plants of Doritaenopsis by methylation-sensitive amplification polymorphism (MSAP) analysis. Vitro Cell. Dev. Biol. Plant 2009, 45, 104-108. [CrossRef]

46. Lu, C.; Li, Y.; Wang, J.; Qu, J.; Chen, Y.; Chen, X.; Huang, H.; Dai, S. Flower color classification and correlation between color space values with pigments in potted multiflora chrysanthemum. Sci. Hortic. 2021, 283, 110082. [CrossRef]

47. Lema-Rumińska, J.; Zalewska, M. Changes in flower colour among Lady Group of Chrysanthemum $\times$ grandiflorum/Ramat./Kitam. as a result of mutation breeding. Folia Hortic. 2005, 17, 61-72.

48. Zalewska, M.; Lema-Rumińska, J.; Miler, N. In vitro propagation using adventitious buds technique as a source of new variability in chrysanthemum. Sci. Hortic. 2007, 113, 70-73. [CrossRef]

49. Kengkarj, P.; Smitamana, P.; Fujime, Y. Assessment of somaclonal variation in chrysanthemum (Dendranthema grandiflora Kitam.) using RAPD and morphological analysis. Plant Tissue Cult. Biotechnol. 2008, 18, 139-149. [CrossRef]

50. Yamaguchi, H.; Shimizu, A.; Degi, K.; Morishita, T. Effects of dose and dose rate of gamma ray irradiation on mutation induction and nuclear DNA content in chrysanthemum. Breed. Sci. 2008, 58, 331-335. [CrossRef]

51. Yamaguchi, H.; Hase, Y.; Tanaka, A.; Shikazono, N.; Degi, K.; Shimizu, A.; Morishita, T. Mutagenic effects of ion beam irradiation on rice. Breed. Sci. 2009, 59, 169-177. [CrossRef]

52. Eeckhaut, T.; Van Houtven, W.; Bruznican, S.; Leus, L.; Van Huylenbroeck, J. Somaclonal Variation in Chrysanthemum $\times$ morifolium Protoplast Regenerants. Front. Plant. Sci. 2020, 11, 2104. [CrossRef]

53. Winiecki, J. Principles of radiation therapy. Phys. Sci. Rev. 2020, in press. [CrossRef] 